\title{
Eagle's Syndrome: A Case Report and Review
}

\author{
Dr. Tarun Vyas ${ }^{1^{*}}$, Dr. Pradeep Vishnoi ${ }^{2}$, Dr. Harshul Joshi ${ }^{3}$ \\ ${ }^{1}$ Asst. Professor, Department of Oral Medicine and Radiology R.R. Dental College \& Hospital, Umarda, \\ Udaipur Rajasthan, India. \\ 2Asst. Professor, R.R. Dental College and Hospital, Udaipur Rajasthan, India. \\ 3 Junior Resident, RNT Medical College and MB, Hospital, Udaipur, India.
}

Case Report Article

Address for Correspondence Author

Dr. Tarun Vyas; Asst. Professor, Department of Oral Medicine and Radiology R.R. Dental College \& Hospital, Umarda, Udaipur Rajasthan, India.

E-mail: tarunvyas14@gmail.com

Crossref doi: https://doi.org/10.36437/ijdrd.2020.2.1.N

\section{ABSTRACT}

Eagle's syndrome is not a usual condition, but less known to physicians, there is symptomatic elongation of the styloid process. Its symptoms are Elongated styloid process syndrome, Dull nagging pain localized in the throat, Pain on extension of tongue, on cervical rotation, radiating to the ear and mastoid region, Foreign body sensation in the throat, etc. We present a case of 45-year male pain in the right sub auricular region for 6 months. The pain was intermittent in nature and aggravated during jaw movements like opening, closing, and mastication. His clinical signs resembled the presentation of Eagle's Syndrome, which were radiologically confirmed by Orthopantomogram and Computed Tomography. Patient undegoes surgical excision.

Keywords: Eagle's Syndrome, Styloid Process, Orthopantomogram.

\section{Introduction}

In 1937, Dr Watt W Eagle, an otolaryngologist focused the attention on elongated styloid process as a source of pain in head \& neck region \& the condition came to be known as Eagle's Syndrome 1 .

Originally Eagle described 2 distinct syndromes:

- The Classic Syndrome:

Generally follows tonsillectomy \& the most common symptom is sensation of a foreign body lodged in the pharynx.

- The Carotid Artery Syndrome:

It doesn't depend upon previous pharyngeal surgery or trauma. Mechanical irritation and stimulation of sympathetic plexus in the walls of the external or internal carotid artery by stylohyoid tip provide a diverse array of symptoms. 
1,2,3Etiology: The exact cause of elongation of the styloid process is not clear. Theories that have been proposed include -Congenital elongation.

- Elongation at the cartilaginous junction.

- Post traumatic reactive hyperplasia ${ }^{4}$

The mineralisation or calcification of styloid process may be unilateral or bilateral and relatively common, occurring in $2 \%-4 \%$ of the generalised population, and may remain asymptomatic, but only a few are symptomatic5. It is generally asymptomatic, occurs in adult patients, with the age ranging from 30 to 50 years, and females are more commonly affected. Styloid process elongation can occur both unilaterally or bilaterally both.6,7. Langlais et al.(1986)8classified elongated styloid process and mineralised styloid complexes based on the radiographic appearance and structures as follows:

\section{Types of Elongated Styloid Process:}

- Elongated- Uninterrupted elongation

- $\quad$ Pseudo articulated -Styloid process is joined to the mineralised stylomandibular or stylohyoid ligament by single pseudo articulation.

- $\quad$ Segmented-Short or long non continuous

\section{Portions of the Styloid Process Anatomy \& Embryological Considerations:}

The normal styloid process is a cylindrical spur of bone that usually tapers gradually towards the pointed free extremity.

* Muscles: Styloglossus, Stylohyoid, Stylopharyngeus

* Ligaments attached: Stylohyoid

Derived from: Hyoid bone9,10. Here, we report a case of the Eagle's syndrome presenting with symptoms of unilateral atypical facial pain, which makes it a case to emphasize on for discussion. Generally, the mainstay of treatment for this is a surgical and non-surgical approach. Here, we report a case treated with medication and physiotherapy.

Case Report: A 45-year-old male presented with a primary complaint pain in the upper neck region on the right side for 6 months. The pain was intermittent in nature and aggravated during jaw movements like opening, closing the mouth and chewing the food. Figure 1. He also experienced pain during turning his head towards left along with difficulty in swallowing. The pain was radiating to the preauricular region. Unremarkable dental and medical history is present in this patient. On an extraoral examination in this inspection, we see that Nodular lesion was found below the angle of the mandible. The skin over lesion appeared stretched Which was otherwise normal. The lesion disappeared on bringing the neck back to normal. On palpation there is Lesion was bony hard, fixed and associated with pain in soft tissue covering it. The patient confirmed that pain elicited on palpation was the same as pain described in chief complaint Figure 2. Bimanual palpation revealed non-palpable lymph nodes bilaterally. Intraoral examination showed Root stumps w.r.t. 36,46,48. and Proximal caries wrt 17,18. Provisional diagnosis as Elongated Styloid process syndrome. A panoramic radiographical examination demonstrated elongation with mild calcification of the bilateral styloid processes. An OPG of the oral cavity revealed an elongated type of Eagle's syndrome on the right side and a segmented type on the left side Figure 3. Furthermore, a plain Computed Tomography (CT) scan of the base of the skull also showed elongated bilateral styloid processes. Temporary relief of symptoms on the infiltration of $1 \mathrm{ml}$ of $2 \%$ lignocaine locally. Radiographic findings-Best viewed by Submentovertex or 
PA view of the mandible with mandible elevated. As the patient initially does not need surgical treatment so we give non-steroidal drugs and anti-inflammatory local treatment. Then surgical excision is done and a Surgically excised segment of the styloid ligament.is there. After 1 to 2 months patient of follow-up, the patient was devoid of any symptoms.

\section{Discussion}

Eagle Syndrome is Elongated styloid process can be a source of craniofacial and cervical pain and remains a diagnostic challenge and uncommon entity 6,7 . The normal length of the styloid process may vary, but with the majority of population it is $20-30 \mathrm{~mm}$ long Eagle's syndrome is the name given to symptomatic elongation of styloid process of more than $25 \mathrm{~mm}$ or mineralization of the stylohyoid or stylomandibular ligament.11,12

However, a $30 \mathrm{~mm}$ or longer process is considered anomalous and responsible for the so-called Eagle syndrome. The epidemiological incidence has been reported to between 1.4-30\%2 13,14. Eagle's syndrome is characterized by the following symptoms: pharyngeal pain localized in the tonsillar fossa, radiating to the oesophagus, to the hyoid bone, painful head rotation and lingual movements. The pain is exacerbated by swallowing and chewing. Other symptoms include dull nagging pain localized in the throat foreign body sensation in the throat 15 and voice change lasting for only a few minutes. A variety of additional symptoms have been reported such as clicking jaw unilateral pain, pain radiating to the neck, to the tongue, chest or temporomandibular joint (TMJ) radiating to subauricular and submandibular region and facial paraesthesia, hypersalivation, sometimes visual problems, dysphagia and pharyngeal spasm. Pain on extension of tongue, on cervical rotation, radiating to ear and mastoid region ${ }^{16}$.In this biopsy can be considered sometimes a little forward planning and thought can greatly improve the diagnostic value obtained 17. Dental and craniofacial radiograph are an important assessment tool in race, gender and stature due diversity in human physical constitutional makeup. With recent advancement of technique such as CT, Micro CT, MRI, and OPG, CBCT also aids in forensic odontology ${ }^{18}$. The differential diagnosis includes Styloid process carotid artery syndrome ,Stylohyoid syndrome.,Styloid process neuralgia, Hyoid Bursitis, migraine headache, glossopharyngeal pain,In this both surgical and non surgical approach is applied. A pharmacological approach by transpharingeal infiltration of steroids or anesthetics in the tonsillar fossa has been used is,.and in this surgical approach is preferred in extra and intra oral oral appraoach 19

\section{Conclusion}

Dentists have an important role to play in the diagnosis of Eagle's syndrome, as the presenting symptoms in a majority of the cases direct patients to a dental consultation. An accurate case history coupled with appropriate radiographic evaluation (OPG, CT scan etc.,) is a must for the diagnosis. In our opinion, surgical treatment is the first choice i.e resection of the elongated styloid process.

\section{References}

1. Bokhari MR, Graham C, Mohseni M. Eagle Syndrome. [Updated 2019 Dec 13]. In: StatPearls [Internet]. Treasure Island (FL): StatPearls Publishing; 2020 Jan-. Available from: https://www.ncbi.nlm.nih.gov/books/NBK430789/

2. Eagles WW. (1948). Elongated styloid process: further observation and a new syndrome. Arch Otolaryngol,47:630-640. 
3. Eagles WW. (1949). Symptomatic elongated styloid process: symptoms and treatment. AMA Arch Otolaryngol, 49: 490-503.

4. Lahori M, Aggarwal P. (2012). Eagle's syndrome. Guident22-25.

5. Sadaksharam J, Singh K. Stylocarotid syndrome: An unusual case report. Contemp Clin Dent 2012;3:503-6.

6. Vougiouklakis T. Overview of the ossified stylohyoid ligament based in more than 1200 forensic autopsies. J Clin Forensic Med 2006;13:268-70.

7. Paraskevas GK, Raikos A, Lazos LM, Kitsoulis P. Unilateral elongated styloid process: A case report. Cases J 2009;2:9-135.

8. Langlais RP, Miles DA, Van Dis ML. Elongated and mineralized stylohyoid ligament complex: A proposed classification and report of a case of Eagle's syndrome. Oral Surgery Oral Medicine Oral Pathology 1986; 61: 527-532.

9. Hollishead WH: Anatomy for Surgeons- The Head and Neck ,Philadelphia,JB Lippincott Co,1982.

10. BernFeld K: Zur Begriffsbestimung and pathogeneseeines neuen krankheitsbildes,des Sog:Styloides sympotomenkomenkomplexs Z Laryg Rhinol 1932;23:107-110.

11. Ilguy M, Ilguy D, Guler N, Bayirli G. Incidence of the type and calcification patterns in patients with elongated styloid process. Journal of International Medical Research 2005; 33: 96-102.

12. Lorman GJ, Biggs JR. The Eagle syndrome. American Journal of Roentgenology 1983; 140: 881-882.

13. Eagle WW. Elongated styloid process. Report of two cases. Archives of Otolaryngology 1937; 25: 584-587.

14. Keur JJ, Campbell JPS, McCarthy JF. The clinical significance of the elongated styloid process. Oral Surgery Oral Medicine Oral Pathology 1986; 61: 399.

15. Quereshy FA, Gold ES, Arnold J, Powers MP. Eagle's syndrome in an 11-year-old patient. Journal of Oral Maxillofacial Surgery 2001; 59: 94-97. Godden DRP, Adam S, Woodwards.

16. Godden DRP, Adam S, Woodwards RTM. Eagle's syndrome: An unusual cause of a clicking jaw. British Dental Journal 1999; 186: 489-490.

17. Vyas T. Biopsy of Oral Lesion -A Review Article. J Adv Med Dent Scie Res 2018;6(1):27-35.

18. Vyas T. Radiographic determination: An upcoming aid in forensic radiology. J Int Clin Dent Res Organ 2019;11:71-5.

19. Németh O, Csáki G, Csadó K, Kivovics P. Case report of a 27-year-old patient suffering from Eagle's syndrome. Oral Health Dent Manag.2010;9:140-3.

How to cite this Article: Dr. Tarun Vyas ${ }^{1 *}$, Dr. Pradeep Vishnoi², Dr. Harshul Joshi ${ }^{3}$, Eagle's

Syndrome: A Case Report and Review

Int. J. Drug Res. Dental Sci., 2020; 2(1):18-22.

Source of Support: Nil, Conflict of Interest: None declared.

Received: 24-1-2020 Revised: 25-2-2020 Accepted: 29-2-2020 


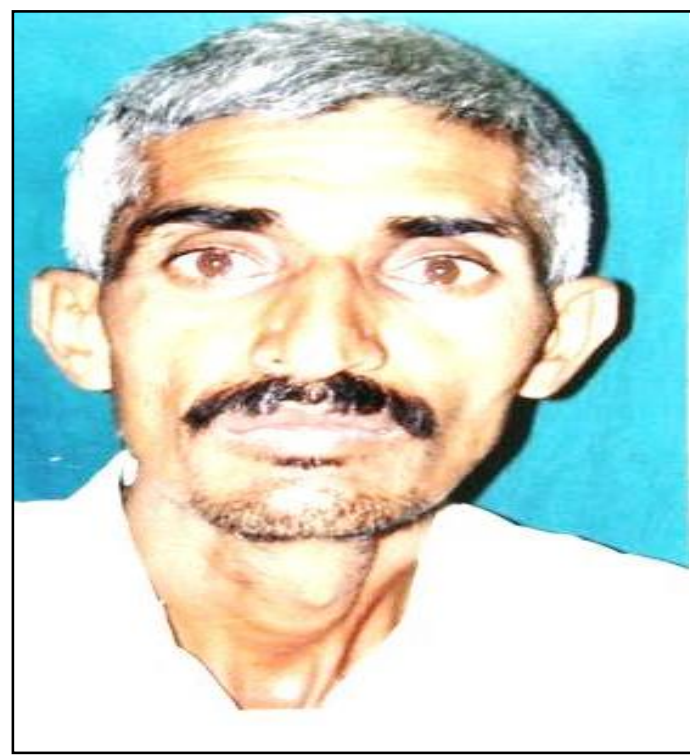

Figure 1: The front profile clinical picture of the patient the right

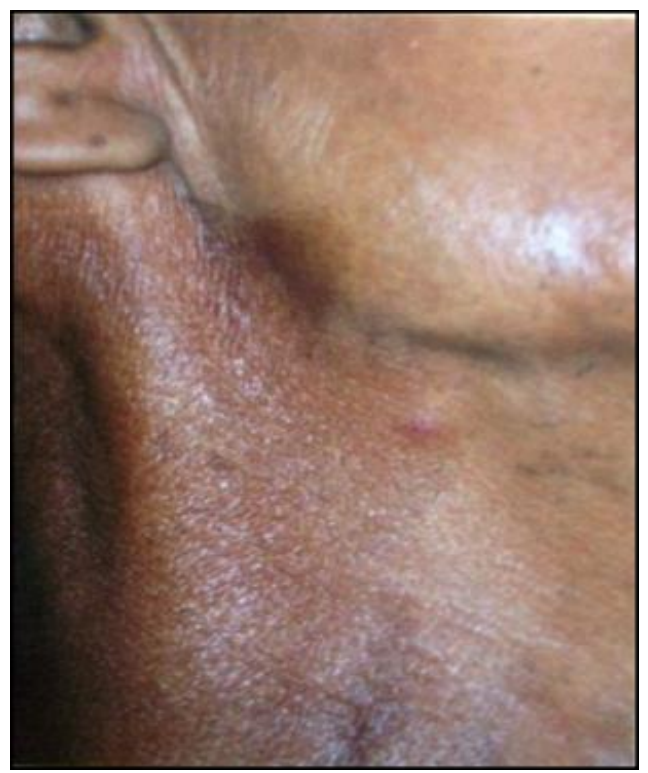

Figure 2: Side profile clinical picture of patient showing a bony mass on the tonsillar fossa region

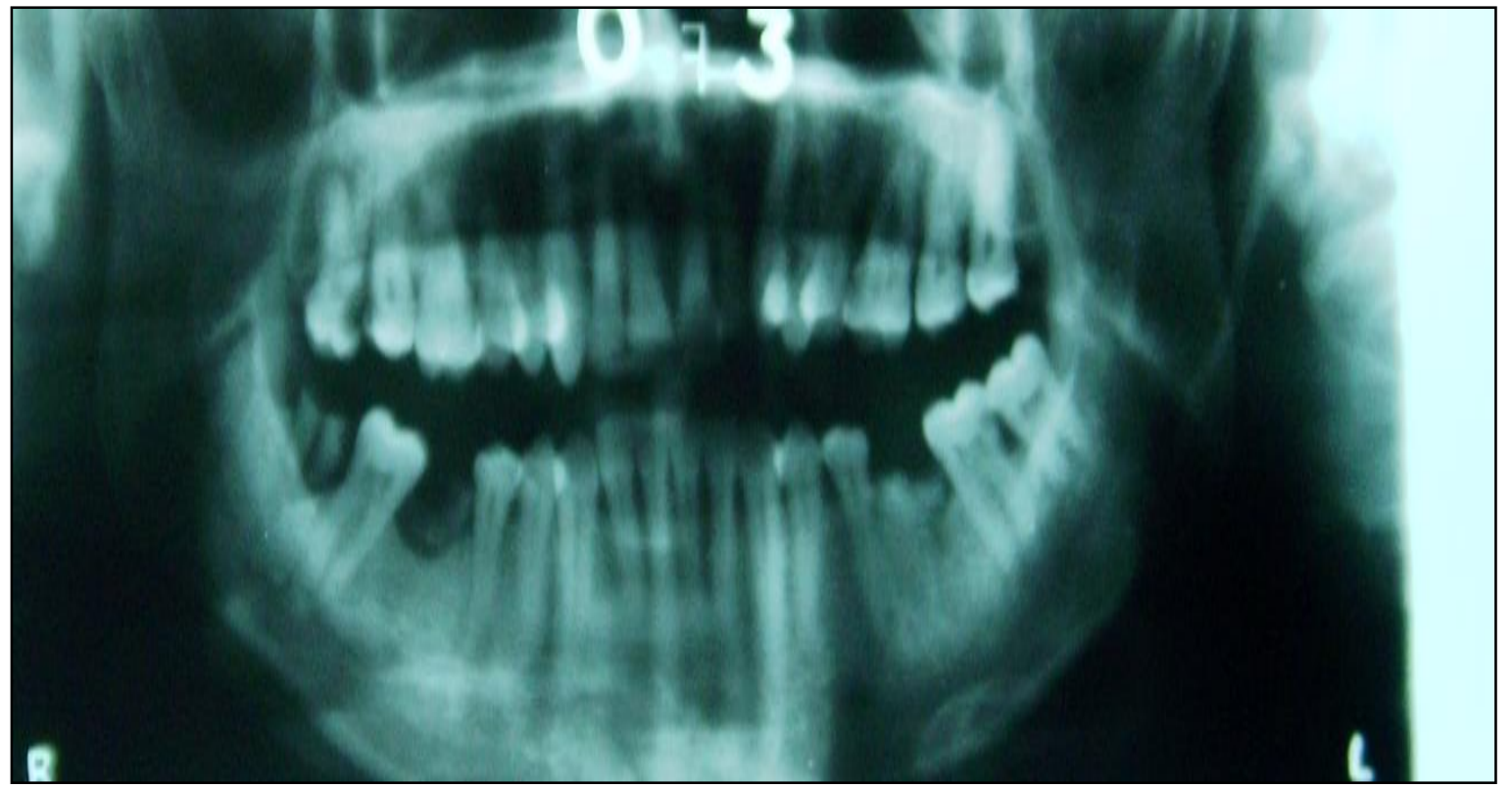

Figure 3: Panoramic radiograph showing elongation with mild calcification of the bilateral styloid processes 